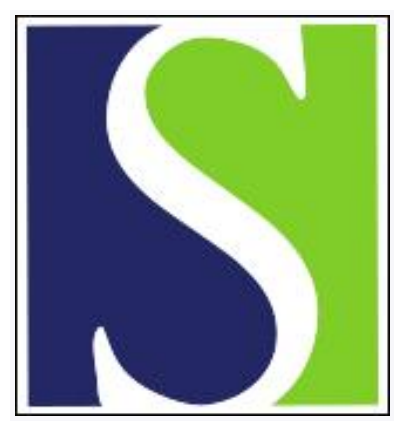

Scand J Work Environ Health 2008;34(5):381-386

https://doi.org/10.5271/sjweh.1284

Issue date: 00 Oct 2008

Occupational exposure to dust, gases and fumes, a family history of asthma and impaired respiratory health

by Hedlund U, Rönmark E, Eriksson K, Lundbäck B, Järvholm B

Affiliation: Occupational and Environmental Medicine, Department of Public Health and Clinical Medicine, Umeå University, SE-901 85 Umeå, Sweden. ulf.hedlund@envmed.umu.se

Key terms: asthma; chronic bronchitis; disease susceptibility; dust; epidemiology; etiologic fraction; family history; fume; gas; impaired respiratory health; occupational exposure; respiratory health; respiratory symptom

This article in PubMed: www.ncbi.nlm.nih.gov/pubmed/18956125 


\title{
Occupational exposure to dust, gases and fumes, a family history of asthma and impaired respiratory health
}

\author{
by Ulf Hedlund, PhD, 1, 2 Eva Rönmark, PhD, 1, 2 Kåre Eriksson, PhD, ${ }^{1}$ Bo Lundbäck, PhD, 2, 3 Bengt \\ Järvholm, $P h D^{1}$
}

\begin{abstract}
Hedlund U, Rönmark E, Eriksson K, Lundbäck B, Järvholm B. Occupational exposure to dust, gases and fumes, a family history of asthma and impaired respiratory health. Scand J Work Environ Health 2008;34(5):381-386.

Objectives This study assessed the impact of occupational exposure to dust, gases, and fumes on respiratory symptoms, obstructive lung diseases, or the use of asthma medication among persons with and without a family history of asthma.

Methods A population-based cohort was followed for 10 years. This study included all 1739 men and 1594 women occupationally active at the first survey. Exposure and respiratory health were assessed from questionnaires. Multiple logistic regression was used to estimate the effects in relation to occupational groups, with age, gender, and smoking habits as possible confounders, using both cross-sectional and longitudinal analyses. The susceptibility to impaired respiratory health was determined from a family history of asthma.

Results A family history of asthma was reported by $27 \%$ of the men and $34 \%$ of the women. Both occupational exposure and a family history of asthma were associated with impaired respiratory health. The etiologic fractions showed that up to about $70 \%$ of the symptoms could be explained by a family history of asthma among those exposed to low levels of air pollutants, as well as among those with high exposure. However, high exposure contributed up to $35 \%$ of the symptoms both among those with and among those without a family history of asthma. The study indicates that the relative risk of occupational exposure to pollutants is similar for both persons with and those without a family history of asthma.

Conclusions The relative risk for impaired respiratory health after exposure to occupational air pollutants seems to be similar for persons with and those without a susceptibility to impaired respiratory health.
\end{abstract}

Key terms asthma; chronic bronchitis; disease susceptibility; epidemiology; etiologic fraction; respiratory symptom.

Several studies have found an association between occupational exposure to dust, gases, and fumes and respiratory health with respect to chronic cough, chronic phlegm, persistent wheeze, breathlessness, asthma, chronic bronchitis, or chronic obstructive pulmonary disease (1-10). It is well known that there are susceptibility factors for impaired respiratory health (eg, persons with a family history of asthma or atopy have an increased risk) (11). However, whether health effects of occupational exposure to air pollutants differ among persons with and those without susceptibility factors has been less studied (11). In this longitudinal populationbased study, we estimated the impact of occupational exposure on respiratory health in a general, adult, occupationally active population with respect to a family history of asthma.

\section{Study population and methods}

The study area was the northernmost county of Sweden, Norrbotten. The average annual temperature is approximately $0^{\circ} \mathrm{C}$. The industrial setting in the area comprises heavy industries, including mining, steel production, forestry, and paper and pulp industries.

1 Occupational and Environmental Medicine, Department of Public Health and Clinical Medicine, Umeå University, Umeå, Sweden.

2 The OLIN Studies, Department of Medicine, Sunderby Central Hospital of Norrbotten, Luleå, Sweden.

3 Department of Internal Medicine/Respiratory Medicine \& Allergology, Sahlgrenska Academy, University of Göteborg, Göteborg, Sweden.

Correspondence to: Dr Ulf Hedlund, Occupational and Environmental Medicine, Department of Public Health and Clinical Medicine, Umeå University, SE-901 85 Umeå, Sweden. [E-mail: ulf.hedlund@envmed.umu.se] 
The study was included in the OLIN (obstructive lung disease in northern Sweden) studies, details of which have previously been published. The study base included a stratified sample of men and women living in eight municipalities in Norrbotten in 1986. It started in the winter of 1986 with a prevalence study in which $86 \%$ of the invited persons responded to a postal questionnaire (12). The study was repeated in the winter of $1996(13-15)$. Of those originally invited to participate in 1985-1986, $72 \%$ took part in both examinations. In these analyses, we have excluded all not occupationally active persons in $1986(\mathrm{~N}=1521)$, such as students, housewives, old-age pensioners, early retirement pensioners, long-standing unemployed persons, and conscripts. Thereafter, the study sample comprised 1739 men and 1594 women born in 1934, 1935, 1949, or 1950 .

\section{Questionnaire}

The questionnaire was based on that of the British Medical Research Council. It included questions about occupations, respiratory symptoms and diseases, the use of respiratory medication, smoking habits, and a family history of asthma (12). The questionnaire has been used in several studies in Baltic and Nordic countries $(13,16)$.

The following definitions and classifications have been used: (i) family history of asthma: a family history of asthma reported in 1986 or 1996; (ii) asthma-like symptoms: report of both attacks of shortness of breath and recurrent wheeze.

Prior and current occupations and the duration of each employment were requested in the questionnaire. Data on the occupational titles before 1986, in 1986, and in 1996 were used and coded according to the Nordic Classification System of Occupations (17). An experienced occupational hygienist (KE) recoded the occupational titles to those with high or low occupational exposure to dust, gases, and fumes.

In the cross-sectional study in 1986, the people highly exposed comprised those who, in or prior to 1986, had been highly exposed. The people with low exposure comprised those who, up to 1986, had always had low exposure. In the follow-up study in 1996, the people highly exposed comprised those who, in or prior to 1996, had been highly exposed. The people with low exposure comprised those who had always had a low level of exposure until 1996.

\section{Analyses}

Statistical analyses were performed using the Statistical Package for the Social Sciences for Windows, release 11.0.0 (SPSS for Windows, SPSS Inc, Chicago, IL,
USA, 2001) and SAS, version 8.12 (SAS Institute, Cary, NC, USA). A multiple logistic regression analysis was used to estimate the odds ratios. The analysis included smoking habits (nonsmokers, ex-smokers, smokers), age (two age groups), and gender as possible confounders. The fits of the models were described by log likelihood. Persons with missing data on occupational exposure, smoking, or a family history of asthma were excluded from the analysis. The analyses were repeated with the inclusion of only never smokers to study a possible residual confounding of smoking. A P-value of $<5 \%$ was considered statistically significant.

Cumulative incidence was calculated as the proportion developing the studied condition between 1986 and 1996 among those who did not have the condition in 1986.

Cumulative remission was calculated as the ratio between those getting rid of the studied condition between 1986 and 1996 among those who had the condition in 1986.

The etiologic fraction (EF) was calculated as $\mathrm{EF}=(\mathrm{OR}-1) / \mathrm{OR}$, where $\mathrm{OR}$ is the odds ratio (18).

The ethics committee at the University and the University Hospital of Northern Sweden in Umeå approved the study.

\section{Results}

\section{Basic characteristics}

In 1986, there were 3333 occupationally active persons, of whom 1333 were classified as highly exposed (1008 men and 325 women, mean age 44 years), whereas 2000 were classified as having low exposure (731 men and 1269 women, mean age 43 years). Altogether 51 of the 3333 persons had stopped working before the 1996 survey, and 1309 persons had changed occupation between 1986 and 1996. The proportions with high exposure were 30\% and 19\% in 1986 and 1996, respectively. Before the 1986 survey, the participants had worked an average of at least 16 years. Between 1986 and 1996, $24 \%$ had changed exposure group. In 1986, there were slightly more smokers and ex-smokers in the highly exposed group. A total of $84 \%$ did not change smoking habits between 1986 and 1996 (table 1). A family history of asthma was reported by $27 \%$ of the men and $34 \%$ of the women.

\section{Cross-sectional study in 1986}

A high prevalence was found of chronic productive cough and physician-diagnosed chronic bronchitis for iron miners, of physician-diagnosed asthma and the use of asthma medication for workers in the paper and pulp 
Table 1. Smoking habits in 1986 and 1986-1996 by exposure.

\begin{tabular}{|c|c|c|c|c|c|c|c|c|c|c|c|}
\hline \multirow{2}{*}{$\begin{array}{l}\text { Exposure up } \\
\text { to } 1986\end{array}$} & \multicolumn{3}{|c|}{1986} & \multicolumn{8}{|c|}{ Smoking habits 1986-1996 } \\
\hline & $\begin{array}{l}\text { Non- } \\
\text { smokers } \\
(\%)\end{array}$ & $\begin{array}{c}\text { Ex- } \\
\text { smokers } \\
(\%)\end{array}$ & $\begin{array}{c}\text { Smokers } \\
(\%)\end{array}$ & $\begin{array}{l}\text { Persistent } \\
\text { nonsmokers } \\
(\%)\end{array}$ & $\begin{array}{l}\text { Persistent } \\
\text { ex-smokers } \\
(\%)\end{array}$ & $\begin{array}{c}\text { Persistent } \\
\text { smokers } \\
(\%)\end{array}$ & $\begin{array}{c}\text { Starters } \\
(\%)\end{array}$ & $\begin{array}{c}\text { Re- } \\
\text { starters } \\
(\%)\end{array}$ & $\begin{array}{c}\text { Quitters } \\
(\%)\end{array}$ & $\begin{array}{c}\text { Unclear } \\
(\%)\end{array}$ & $\begin{array}{c}\text { Unchanged } \\
\text { smoking } \\
\text { habits } \\
(\%)\end{array}$ \\
\hline High & 36 & 27 & 38 & 33 & 26 & 23 & 0.7 & 2.0 & 14 & 1.4 & 85 \\
\hline Low & 44 & 23 & 33 & 41 & 23 & 22 & 0.6 & 2.1 & 11 & 1.0 & 82 \\
\hline Total & 41 & 24 & 35 & 37 & 24 & 22 & 0.6 & 2.0 & 13 & 1.1 & 84 \\
\hline
\end{tabular}

Table 2. Cross-sectional study in 1986 — prevalence and odds ratios (OR) for combinations of a family history of asthma (FHA) and occupational exposure to dust, gases, and fumes in a multiple logistic regression with adjustment for age and gender. (exp $=\operatorname{exposure,~} 0 R_{E}$ $=$ odds ratio for occupational exposure, $\mathrm{OR}_{\mathrm{F}}=$ odds ratio for a family history of asthma, $\mathrm{OR}_{\mathrm{EF}}=$ odds ratio for the combined effect)

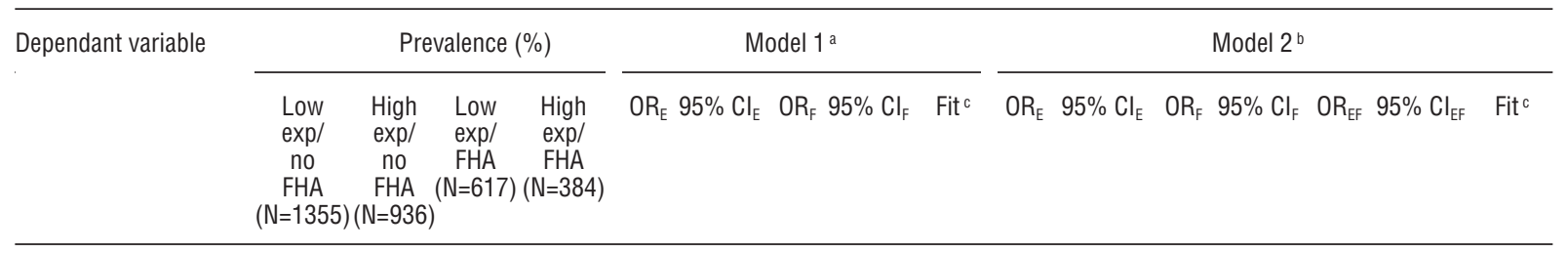

\begin{tabular}{|c|c|c|c|c|c|c|c|c|c|c|c|c|c|c|}
\hline $\begin{array}{l}\text { Attacks of short- } \\
\text { ness of breath }\end{array}$ & 6.6 & 8.8 & 15 & 21 & $1.6 \quad 1.2-2.0$ & 2.5 & $2.0-3.2$ & 2066 & 1.5 & $1.1-2.1$ & 2.4 & $1.8-3.3$ & $1.10 .66-1.7$ & 2066 \\
\hline Recurrent wheeze & 7.2 & 12 & 16 & 24 & $1.51 .2-1.9$ & 2.4 & $1.9-3.0$ & 2074 & 1.5 & $1.1-2.1$ & 2.5 & $1.8-3.4$ & $0.96 \quad 0.61-1.5$ & 2073 \\
\hline Asthma-like symptoms & 3.8 & 5.6 & 11 & 14 & $1.41 .0-1.9$ & 2.9 & $2.1-3.8$ & 1405 & 1.5 & $0.95-2.2$ & 3.0 & $2.0-4.6$ & $0.880 .49-1.6$ & 1405 \\
\hline Longstanding cough & 7.0 & 8.7 & 11 & 13 & $1.30 .95-1.7$ & 1.6 & $1.2-2.0$ & 1873 & 1.3 & $0.95-1.8$ & 1.6 & $1.2-2.3$ & $0.97 \quad 0.58-1.6$ & 1873 \\
\hline Sputum production & 13 & 20 & 23 & 30 & $1.51 .2-1.8$ & 1.8 & $1.5-2.2$ & 2764 & 1.6 & $1.2-2.0$ & 1.9 & $1.5-2.5$ & $0.860 .58-1.3$ & 2764 \\
\hline $\begin{array}{l}\text { Chronic productive } \\
\text { cough }\end{array}$ & 2.3 & 3.4 & 4.2 & 4.0 & $1.30 .81-1.9$ & 1.5 & $1.0-2.3$ & 877 & 1.5 & $0.88-2.6$ & 1.8 & $1.1-3.1$ & $0.64 \quad 0.28-1.5$ & 876 \\
\hline $\begin{array}{l}\text { Physician-diagnosed } \\
\text { asthma }\end{array}$ & 3.0 & 3.2 & 8.0 & 8.7 & $1.10 .79-1.6$ & 2.8 & $2.0-3.9$ & 1190 & 1.1 & $0.67-1.8$ & 2.7 & $1.8-4.2$ & $1.10 .55-2.1$ & 1190 \\
\hline $\begin{array}{l}\text { Use of asthma } \\
\text { medication }\end{array}$ & 2.7 & 3.2 & 9.1 & 8.1 & $1.20 .82-1.7$ & 3.1 & $2.2-4.3$ & 1178 & 1.4 & $0.82-2.3$ & 3.5 & $2.3-5.3$ & $0.77 \quad 0.39-1.5$ & 1178 \\
\hline $\begin{array}{l}\text { Physician-diagnosed } \\
\text { chronic bronchitis }\end{array}$ & 2.1 & 3.6 & 3.3 & 7.1 & $1.91 .2-2.8$ & 1.8 & $1.2-2.6$ & 908 & 1.7 & $0.97-2.8$ & 1.5 & $0.86-2.7$ & $1.30 .60-2.9$ & 908 \\
\hline
\end{tabular}

a Includes dummy variables for exposure and FHA.

b Includes dummy variables for exposure and FHA, and the combined effect.

c Estimated by -2 log likelihood.

industries, and of chronic productive cough for farmers (data not shown).

In the multivariate analysis, respiratory health was impaired by both occupational exposure and family history of asthma (table 2). An analysis restricted only to nonsmokers showed similar results, except for physiciandiagnosed chronic bronchitis, for which there were no increased risks (data not shown). The odds ratios for the combined effect of a family history of asthma and exposure were not significant, and the fit of the model did not increase significantly. This finding indicates that the relative risks of exposure were similar for the persons with and those without a family history of asthma (table 2).

\section{Longitudinal study, 1986 to 1996}

Incidence. The cumulative incidences increased more among those with high exposure and with a family history of asthma, showing a pattern similar to that of the cross-sectional analyses (table 3 ). The analysis showed increased risks for all symptoms and diagnoses among the exposed persons; however, the odd ratios were only significantly increased for some symptoms. The analysis did not show any better fit if the second model and the odds ratios for the combined effect of a family history of asthma and exposure were not significant. An analysis of only nonsmokers showed similar results (data not shown).

Risk factors other than occupational exposure. The odds ratios for other major risk factors used in the model, such as age, gender, a family history of asthma, and smoking habits, were not very different from what we have recently published in a similar study of socioeconomic status based on the same material (no new data shown) (19).

Etiologic fraction. When the odds ratios were transformed to etiologic fractions, it was obvious that a fam- 
Table 3. Longitudinal study from 1986 to 1996 — cumulative incidence and odds ratios (OR) for combinations of without or with a family history of asthma (FHA) and occupations with high or low exposure to dust, gases, and fumes in a multiple logistic regression with adjustment for age, smoking, and gender. $\left(0 R_{E}=\right.$ odds ratio for occupational exposure, $0 R_{F}=$ odds ratio for a family history of asthma, $\mathrm{OR}_{\mathrm{EF}}=$ odds ratio for the combined effect)

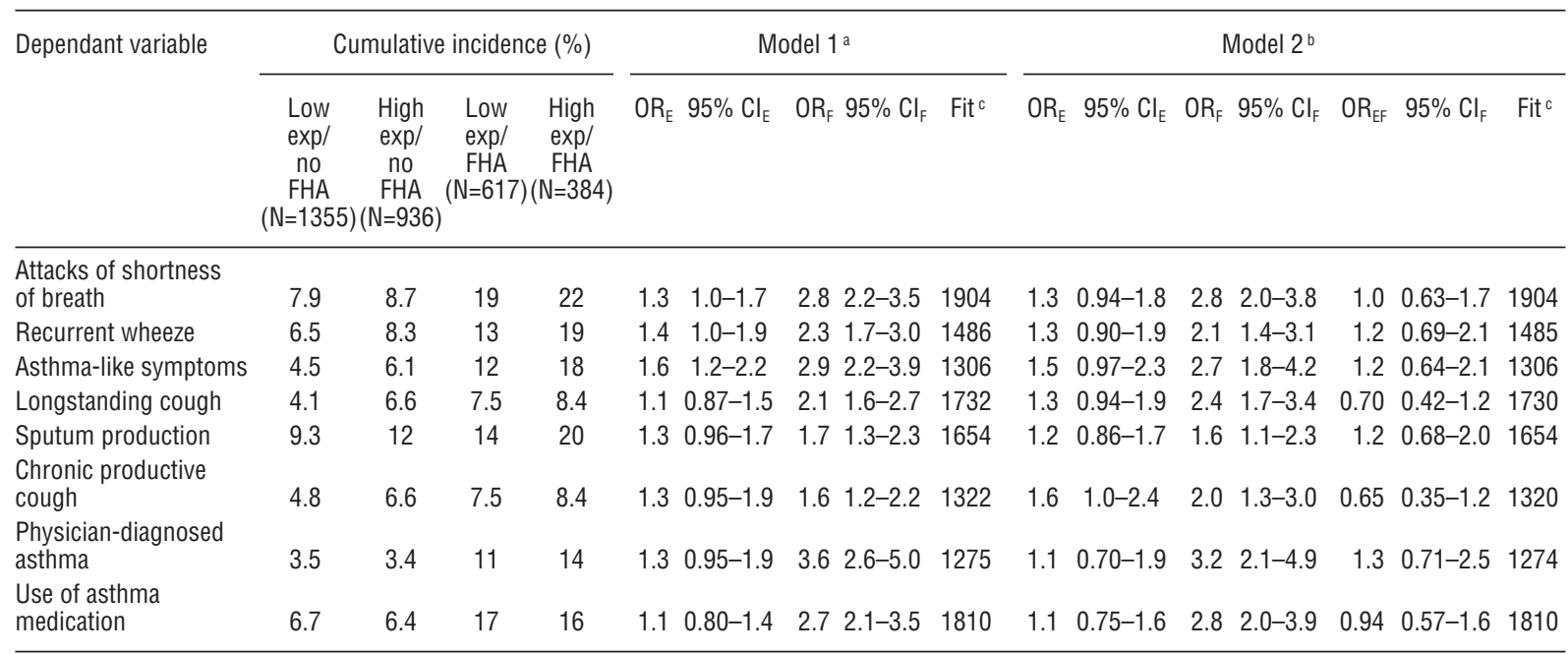

a Includes dummy variables for exposure and FHA.

b Includes dummy variables for exposure and FHA, and the combined effect.

c Estimated by -2 log likelihood.

ily history of asthma explained more of the occurrence of these symptoms than occupational exposure in this population. A relative risk of up to 3.6 indicated that up to about $70 \%$ of the symptoms could be explained by a family history of asthma, both for those with low exposure and those with high exposure. A relative risk of 1.6 indicated that high exposure contributed up to about $35 \%$ of the symptoms.

Remission. Cumulative remission was lowest for physician-diagnosed asthma and the use of asthma medication, $10 \%$ and $14 \%$, respectively. Otherwise the median was $37 \%$, and the range was $21-72 \%$, the highest value occurring for chronic productive cough. The number of incident cases was found for physician-diagnosed asthma and the use of asthma medication, 12 and 14 times higher, respectively, than for the remittent cases. For other symptoms, the corresponding figures were lower, the median being 2.5 and the range being 1.2-4.6.

\section{Discussion}

This population-based cohort study of occupationally active workers showed that respiratory health is impaired by occupational exposure to dust, gases, and fumes among persons with and those without a family history of asthma.

Our findings of an association between occupational exposure and respiratory health are in accordance with the results of other studies (1-10). Other populationbased cross-sectional studies have found odds ratios of 1.8 to 3.2 for asthma after exposure to dust, gases, and fumes $(4,5)$, and, in one of them, an exposure-response relationship was found (5). Results based on longitudinal studies are still few. A study from Norway found an increased risk of 1.6 for developing asthma among workers exposed to dust, gases, and fumes (9). A Finnish study based on the Medication Reimbursement Register of the Social Insurance Institution of Finland, the Finnish Register of Occupational Diseases, and Finnish population census data from 1985, 1990, and 1995 found an increased incidence of asthma especially in manufacturing, service, and agricultural work, ranging from 1.53 to 2.12 for men and from 1.33 to 1.84 for women when administrative work was used as the reference group (8).

Estimating exposure from occupational titles is a crude method. Our characterization of exposure does not take into account either the cumulative exposure or the very different kinds of exposures. As the classification of exposure was blinded according to outcome, there is a low risk of differential bias due to the classification of exposure. A nondifferential misclassification of exposure tends to decrease the risk estimates. Other population studies have, as we have, used occupational titles for estimating exposure (3). Some studies have used data from interviews (1) or persons' self-reported exposures $(4,9)$. Both when and for how long a time people have been exposed vary in different studies. We have classified a person as highly exposed if he or she has ever worked 
in a highly exposed job, a method used by other authors $(4,9)$. Other studies have based their results on the last occupation $(7,20)$, the longest-held occupation (21), or the occupation during the first 5 years of a follow-up (2). The choice of method may affect the results. When we ignored exposure from occupations held before the survey in 1986, the effects of exposure were somewhat weaker. This finding indicates that also exposure for a long time before the survey may have had effects. This finding is also in accordance with our previous results, in which retired miners had an increased prevalence of respiratory symptoms (22) and respiratory symptoms were more common among ex-smokers than among nonsmokers (23).

As expected, we found a family history of asthma to be a strong determinant of respiratory health, especially for asthma, and this finding agrees with the results of other studies $(13,15,19,22,24)$. As people with a family history of asthma have a higher risk of impaired respiratory health a priori, the risk in absolute terms is higher among the susceptible persons. We do not believe our results should be interpreted as a cause for counseling susceptible persons to avoid working in environments with high exposure to dust, gases, or irritants. Rather it shows that preventive measures to reduce exposure are beneficial both for susceptible and nonsusceptible persons. On the other hand, the environment as a possible cause of impaired respiratory health should not be neglected among persons with a susceptibility for airway disease, and reducing the exposure should be one option in the therapeutic arsenal.

The studied variables can be classified as asthmatic variables (attacks of shortness of breath, recurrent wheeze, asthma-like symptoms, physician-diagnosed asthma, and the use of asthma medication) and as bronchitic variables (longstanding cough, sputum production, chronic productive cough, and physician-diagnosed chronic bronchitis). The symptoms often overlap. Bronchitic symptoms are strongly associated with smoking. We had no data on pack-years, and therefore the smoking data (classified as never smoker, ex-smoker, and smoker) was used in the adjusted analyses. To study possible unadjusted confounding for smoking, we repeated the analysis for nonsmokers only. The power was much lower, but the findings indicated that the possible unadjusted confounding of smoking was weak.

Risks can be expressed as odds ratios or etiologic fractions. An etiologic fraction indicates how much of a condition could be prevented if the determinant could be eliminated (18). For attacks of shortness of breath and recurrent wheeze, etiologic fractions of about $15 \%$ have been reported in cross-sectional studies $(21,25)$. In a Norwegian longitudinal study these figures were about $5 \%$ to $10 \%$, and for sputum production, chronic productive cough, and physician-diagnosed asthma they were about $15 \%$ (9). A Finnish longitudinal population study found $29 \%$ for men and $17 \%$ for women (8). When the wide confidence intervals are considered, our findings are similar in size.

In summary, the study shows that occupational exposure to dust, gases, and fumes is a determinant of respiratory health both for persons with and for those without the susceptibility factor of a family history of asthma.

\section{Acknowledgments}

The authors thank the staff of the OLIN Studies for collecting the material.

The study was supported by grants from the Swedish Heart-Lung Foundation, the Swedish Asthma-Allergy Foundation, the Swedish Council for Working Life (RALF), and Norrbotten's Local Health Authority.

\section{References}

1. Korn RJ, Dockery DW, Speizer FE, Ware JH, Ferris Jr BG. Occupational exposures and chronic respiratory symptoms: a population-based study. Am Rev Respir Dis. 1987;136(2):298304.

2. Krzyzanowski M, Jedrychowski W. Occupational exposure and incidence of chronic respiratory symptoms among residents of Cracow followed for 13 years. Int Arch Occup Environ Health. 1990;62(4):311-7.

3. Vestbo J, Knudsen KM, Rasmussen FV. The effect of smoking and occupation on changes in respiratory symptoms in middleaged Danish men. Eur Respir J. 1990;3(8):880-5.

4. Bakke P, Eide GE, Hanoa R, Gulsvik A. Occupational dust or gas exposure and prevalences of respiratory symptoms and asthma in a general population. Eur Respir J. 1991;4(3):2738.

5. Xu X, Christiani DC, Dockery DW, Wang L. Exposure-response relationships between occupational exposures and chronic respiratory illness: a community-based study. Am Rev Respir Dis. 1992;146(2):413-8.

6. Garshick E, Schenker MB, Dosman JA. Occupationally induced airways obstruction. Med Clin North Am. 1996;80(4):851-78.

7. Kogevinas M, Anto JM, Sunyer J, Tobias A, Kromhout $\mathrm{H}$, Burney P. Occupational asthma in Europe and other industrialised areas: a population-based study. Lancet. 1999;353(9166):1750-4.

8. Karjalainen A, Kurppa K, Martikainen R, Klaukka T, Karjalainen J. Work is related to a substantial portion of adult-onset asthma incidence in the Finnish population. Am J Respir Crit Care Med. 2001;164(4):565-8.

9. Eagan TM, Gulsvik A, Eide GE, Bakke PS. Occupational airborne exposure and the incidence of respiratory symptoms and asthma. Am J Respir Crit Care Med. 2002;19(4):933-8.

10. Mapp CE, Boschetto P, Maestrelli P, Fabbri LM. Occupational asthma [review]. Am J Respir Crit Care Med. 
2005;172(3):280-305.

11. London SJ. Gene-air pollution interactions in asthma. Proc Am Thorac Soc. 2007;4:217-20.

12. Lundbäck B, Nyström L, Rosenhall L, Stjernberg N. Obstructive lung disease in northern Sweden: respiratory symptoms assessed in a postal survey. Eur Respir J. 1991;4(3):257-66.

13. Lindström M, Kotaniemi J, Jönsson E, Lundbäck B. Smoking, respiratory symptoms, and diseases : a comparative study between northern Sweden and northern Finland: report from the FinEsS study. Chest. 2001;119(3):852-61.

14. Ronmark E, Jonsson E, Lundback B. Remission of asthma in the middle aged and elderly: report from the Obstructive Lung Disease in Northern Sweden study. Thorax. 1999;54(7):6113.

15. Lundbäck B, Rönmark E, Jönsson E, Larsson K, Sandström $\mathrm{T}$. Incidence of physician-diagnosed asthma in adults—a real incidence or a result of increased awareness? Report from The Obstructive Lung Disease in Northern Sweden Studies. Respir Med. 2001;95(8):685-92.

16. Meren M. Asthma, chronic bronchitis and respiratory symptoms among adults in Estonia according to a postal questionnaire. Respir Med. 2001;95(12):954-64.

17. Labor Market Board. Nordisk yrkesklassificering: Svensk grundstandard [Nordic occupational classification: Swedish base standard]. Stockholm: Labor Market Board; 1983.

18. Rothman KJ, Greenland S. Modern epidemiology. 2nd ed. Philadelphia (PA): Lippincott-Raven; 1998.

19. Hedlund U, Eriksson K, Rönmark E. Socio-economic status is related to incidence of asthma and respiratory symptoms in adults. Eur Respir J. 2006;28(2):303-10.

20. Krzyzanowski M, Kauffmann F. The relation of respiratory symptoms and ventilatory function to moderate occupational exposure in a general population: results from the French PAARC study of 16,000 adults. Int J Epidemiol. 1988;17(2):397-406.

21. Trupin L, Earnest G, San Pedro M, Balmes JR, Eisner MD, Yelin E, et al. The occupational burden of chronic obstructive pulmonary disease. Eur Respir J. 2003;22(3):462-9.

22. Hedlund U, Järvholm B, Lundbäck B. Persistence of respiratory symptoms in ex-underground iron ore miners. Occup Med (Lond). 2006;56(6):380-5.

23. Willemse BW, Postma DS, Timens W, ten Hacken NH. The impact of smoking cessation on respiratory symptoms, lung function, airway hyperresponsiveness and inflammation. Eur Respir J. 2004;23(3):464-76.

24. Pallasaho P, Lundbäck B, Läspä SL, Jönsson E, Kotaniemi J, Sovijärvi AR, et al. Increasing prevalence of asthma but not of chronic bronchitis in Finland? Report from the FinEsS-Helsinki Study. Respir Med. 1999;93(11):798-809.

25. Balmes J, Becklake M, Blanc P, Henneberger P, Kreiss K, Mapp C, et al. American Thoracic Society Statement: occupational contribution to the burden of airway disease. Am J Respir Crit Care Med. 2003;167(5):787-97.

Received for publication: 29 November 2006 